\title{
6 \\ BarkTV: Portrait of an innovator
}

\author{
Jennifer Deger
}

In his book Multiple arts, Jean-Luc Nancy describes the portrait as 'first and foremost an encounter', though in fact, as Nancy clearly appreciates, the art of portraiture puts multiple encounters into play. ${ }^{1}$ The most obvious is that between the viewer and the subject of the artwork, an experience often charged with an unnerving immediacy.

Yet all portraits await viewers already imprinted with the echo of encounter. More than most, this is an art form that calls attention to the relationship between artist and subject: two people united in a shared project of portrayal. It is into this prefigured relationship that the viewer enters, assuming the vantage point of an artist who never completely vacates their place. Nancy describes this effect as the artist occupying the foreground of the canvas. From here, the viewer faces the figure before them: another being presenting themselves for encounter.

1 Jen-Luc Nancy, Multiple arts, Stanford, Stanford University Press, 2006. 
As these dynamic relations structure portraiture (even, I would suggest, when the face does not look directly out, or when there is no face at all), it becomes an art without objects, only subjects. Herein lies a strangely unsettling source of their allure: portraits seem to offer some kind of direct experiential encounter with an other even though there can be no mistaking the work of mediation involved.

For Nancy, though, portraiture's most compelling, and defining, encounter occurs elsewhere: namely, between the depicted figure and themselves. Portraits, after all, concern something more, something deeper, than merely a figure posed for public view. The portrait artist's true purpose is neither mutuality, nor resemblance. It is character: that complex inner tangle of qualities that mark individuals as at once unique and yet deeply, and recognisably, human. ${ }^{2}$ And so Nancy identifies the portrait as an art concerned with the 'extraction' of character, as artists work the tremulous surface of the subject in pursuit of an inner but somehow indelible relationship between a self and itself. Character in this reckoning exceeds what someone might be comfortable with - or capable of - publicly portraying to others. For Nancy what is at stake in portraiture is the depiction of a 'singular trait of an intimate disunion'. ${ }^{3}$ From this perspective, the work of portraiture involves a breaking past the veneer of self-presentation in order to reveal the fundamental disunity of the self. This becomes portraiture's defining point of tension. This is where the life lies.

Nancy puts it this way: "Art" is the name of this fragile other encounter. $^{\prime 4}$

2 As Marcia Pointon points out, it is only since the Renaissance that portraiture has been expected to reveal character along with status and identity: '[F]rom the Renaissance to our own day, portraiture carries a huge burden of expectation: a process of comparing and matching takes place as viewers (guided by curators and media commentators) construct an empathetic narrative based on fragments of data from a life set alongside the portrait image, the one illuminating the other.' Marcia Pointon, Portrayal and the search for identity, London, Reaktion, 2012, p. 15.

3 Nancy, 2006, p. 246, emphasis added.

4 Nancy, 2006. Of course ethnography has likewise been defined in terms of encounter. See for instance Michael Jackson, Minima ethnographica: Intersubjectivity and the anthropological project, Chicago, University of Chicago Press, 1998; and Franca Tamisari, 'Body, vision and movement: In the footprints of the ancestors', Oceania, vol. 68, no. 4, 1998, pp. 249-70. 

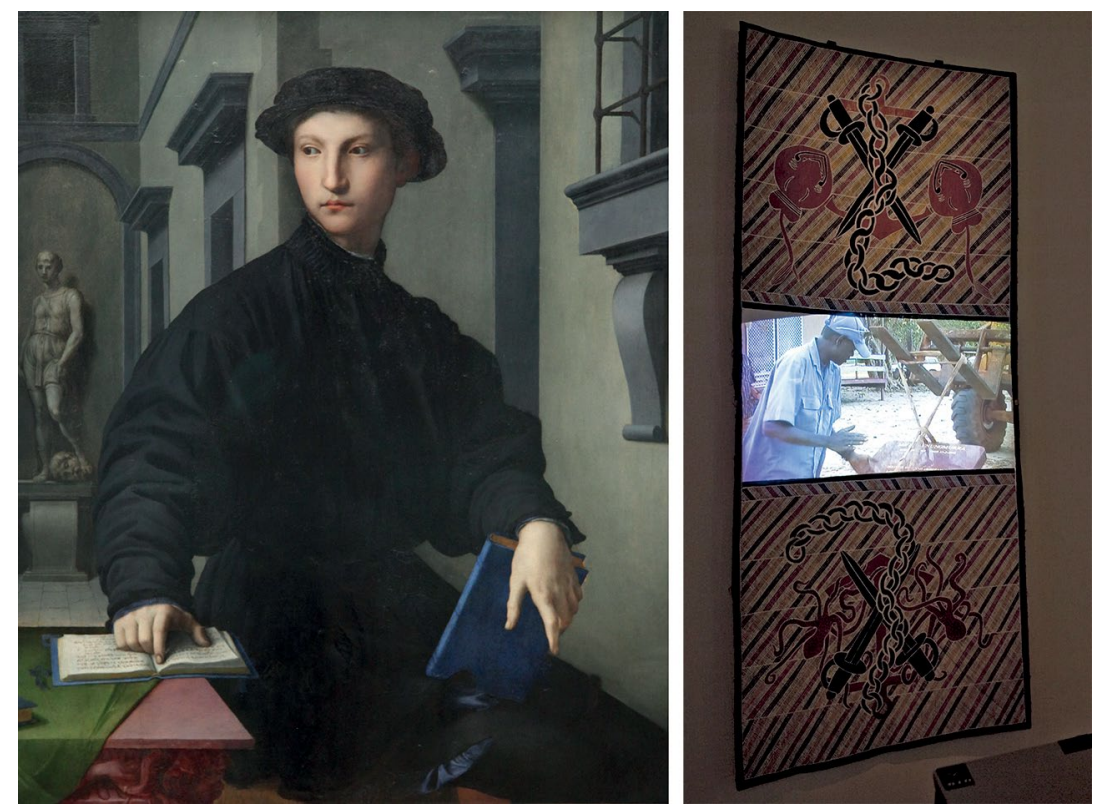

Figure 6.1: Left: Portrait of Ugolino Martelli, Angelo Bronzino, 1536 or 1537, oil on wood, oil on poplar wood.

Source: Wikimedia Commons.

Figure 6.2: Right: Djalkiri \#1, David Bukulatjpi, Jennifer Deger and Marrawakamirr Marrawungu, 2009, video and acrylic on bark.

Source: Courtesy of the artists.

II

This essay is an attempt to flesh out the possibilities of encounter engendered by a mixed-media artwork that my collaborators and I labelled Djalkiri \#1, but is nicknamed the BarkTV. ${ }^{5}$ I present it here,

5 This is by no means an unprecedented argument. See Melinda Hinkson, 'Seeing more than black and white: Picturing Aboriginality at Australia's National Portrait Gallery', Australian Humanities Review, vol. 49, 2010, pp. 5-28, who claims certain Aboriginal painting styles as portraiture as a means of disrupting the normative vision of cultural institutions such as the National Portrait Gallery. John von Sturmer, on the other hand, has dismissed the suggestion that bark paintings are portraits. See John von Sturmer, 'A limping world: Works in the Arnott's collection - some conceptual underpinnings', in They are meditating: Bark paintings from the MCA's Arnott's Collection, Sydney, Museum of Contemporary Art, 2008, pp. 35-53. In exploring this argument here I am concerned with activating the relationship between images and other images as much as the relationship between image and stories that are more usually offered in the exegesis of Aboriginal art. 
in the context of a collection of responses to digital portraiture, with conflicting impulses. Claiming Djalkiri \#l as portrait feels immediately constraining, if not downright colonising. If, as art historian Marcia Pointon argues, portraiture is one of the 'great defining metaphors of Western culture', ${ }^{6}$ then why impose the category at all? What might be gained? What will be obscured, obliterated even, in the process?

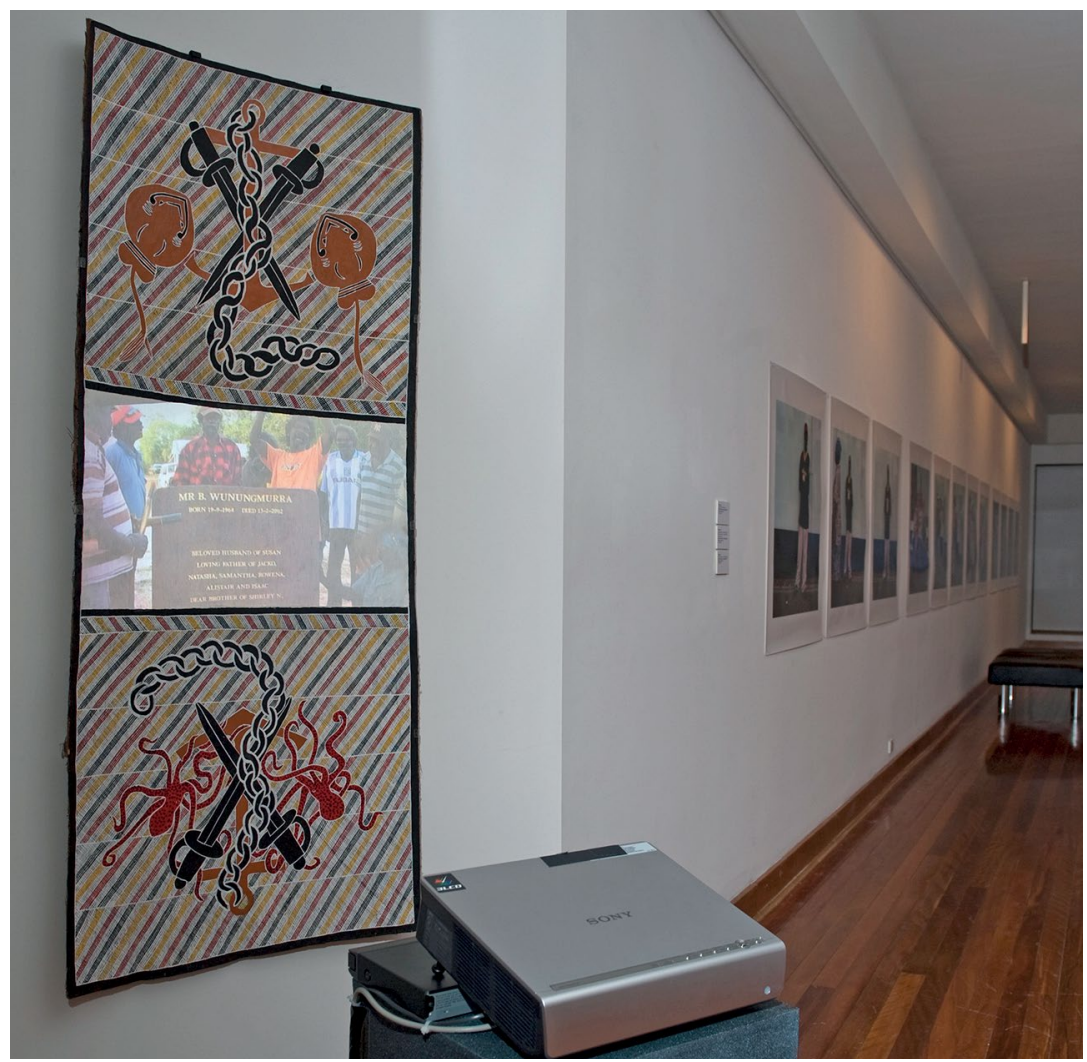

Figure 6.3: Djalkiri \#1, Macquarie University Art Gallery, December 2009. Source: Courtesy of the artists.

Certainly from a purely formal perspective, there is no obvious resemblance between our BarkTV and, for example, Bronzino's delicate masterpiece Portrait of Ugolino Martelli, a work I first came to know through my reading of Nancy. ${ }^{7}$ Yet the more I think about this kind of

6 Pointon, 2012, p. 26.

7 I choose to use it here, though, because I especially like the way it sits beside our bark work. I am surprised how they seem, somehow, strangely akin. 
art, the more I realise that portrait artists and the Aboriginal people of Arnhem Land do share common concerns, most particularly with the art of discerning - and creatively bringing to light - the inner qualities of a person. Cultivating particular ways of seeing, both bring creative energy to the work of rendering visible distinctive marks of character; driven by revelatory purpose, both seek to manifest visible forms of likeness that tap into a power exceeding that of literal resemblance.

And so I begin with a tentative conclusion that there is something to be gained - maybe even something to be seen anew? - by approaching Djalkiri $\# 1$ as if it is a portrait.

\section{III}

On first encountering Djalkiri \#1 the sound might be the first thing that hits you, an energetic urgency of men's ritual song punctuated by the striking of steel on steel. Or maybe, as it was for me when we flipped the 'on' switch for the first time, it will be the glow of the striated surface that catches your eye, the way the images seem to emanate from within the bark itself. Or maybe, you will be drawn closer for a second look by the force of sheer novelty.

Far less likely is that you, my imaginary art gallery visitor, will approach this multimedia installation because of its appeal as a portrait, for this is simply not the way the work appears to present itself. Where is the face? The figure? The person?

Instead, what you will encounter is a long, vertical, three-panelled bark painting, its middle section filled with a looped video projection. The sound comes from speakers built into the projector. It shouldn't take long to work out that this is an Aboriginal headstone-laying ceremony. The nine-and-a-half minute single-take video shows a forklift being used to slowly lift and position the stone while men sing to the beat of clap sticks. The man in an orange T-shirt leading the ritual uses the bottom end of a shifting spanner to strike the steel blade of a tomahawk held above his head. This use of tools as practical instruments - in every sense of the word - is one of the aspects of the work much remarked upon by gallery visitors. 
The top and bottom panels feature octopuses and stingrays darting beside long-bladed knives rakishly crossed over a heavy-chained anchor, the in-between spaces backfilled with ochre-coloured crosshatching. It's a dance of intertwinement that confounds conventional expectations regarding the traditional stuff of Indigenous material culture. In fact, if you look closely you might notice that the paint on the top and bottom panels is acrylic rather than ochre, ochre remaining de rigueur for barks produced for sale in the fine art market.

The video itself is observational in style - traditionally ethnographic, one might say. The camera quietly moves across the scene following the unfolding events. I shot it myself and use it here with permissions from both the relevant Dhalwangu clan leaders and the orange-shirted djungaya (ritual manager).

It would be a mistake to see these elements as either evidence of a playful cultural hybridity or an example of the degeneration of traditional forms. As each one of the men and women in this video would tell you, this is Yolngu rom (law, culture, ancestral precedent). The anchor and the knives and the sea creatures belong together, as do the grader and the shifting spanner, and by extension the bark and the video. Any explanation as to why this is the case, however, would likely be brief and guarded. Some say these images are the result of the history of exchange between Yolngu and Macassan fishermen. Others insist that it is really about relations between Yolngu and Balanda (non-Aboriginal, white people). But all agree that the incorporation of ostensibly foreign material culture has deep ancestral significance. ${ }^{8}$ The objects depicted relate to the activities of Birrinydji, the ancestral sea captain, blacksmith and swordsman who sailed across Arnhem Land, dropping anchor at several places, including the Dhalwangu homeland of Gurrumurru. ${ }^{9}$ Stories associated with Birrinydji and the origins of Yolngu ownership and mastery of 'foreign technologies' are dhuyu (sacred, restricted and dangerous) among my friends and

8 For an analysis and elaboration of what he calls the 'Birrinydji legacy' given to him by Warramirri clan leaders on neighbouring Elcho Island, see Ian McIntosh, 'The iron furnace of Birrinydji', in Alan Rumsey and James Weiner (eds), Mining and Indigenous lifeworlds in Australia and Papua New Guinea, Oxon, Sean Kingston Publishing, 2004, pp. 12-30.

9 Some Yolngu and some anthropologists have suggested that because of their associations with Birrinydji, Yirritja clans - or perhaps certain Yirritja clans - are directly associated with innovation and technological incorporation, while those from the opposite moiety, Dhuwa, are inherently more conservative. My own Yolngu collaborators are reluctant to make such distinctions. 
colleagues. But at any Dhalwangu funeral you will encounter people singing and dancing foundational events involving such items as knives, steel axes, telescopes, cloth and tobacco.

\section{IV}

'The ancestral' is hardly an adequate term to describe the sources of the ongoing and often highly reflexive dynamics of becoming in Yolngu life - and death-including, increasingly, digital practices. But it offers a place to begin. For now, perhaps the most important thing to say is that just as ancestral form and power inhere in country, sacred objects and painted designs, they also materially manifest in people themselves, through physical characteristics and even ways of thinking: ancestral identities emerge and become visible in the breadth of a nose, the tenor of a voice or the brilliance of an idea.

\section{V}

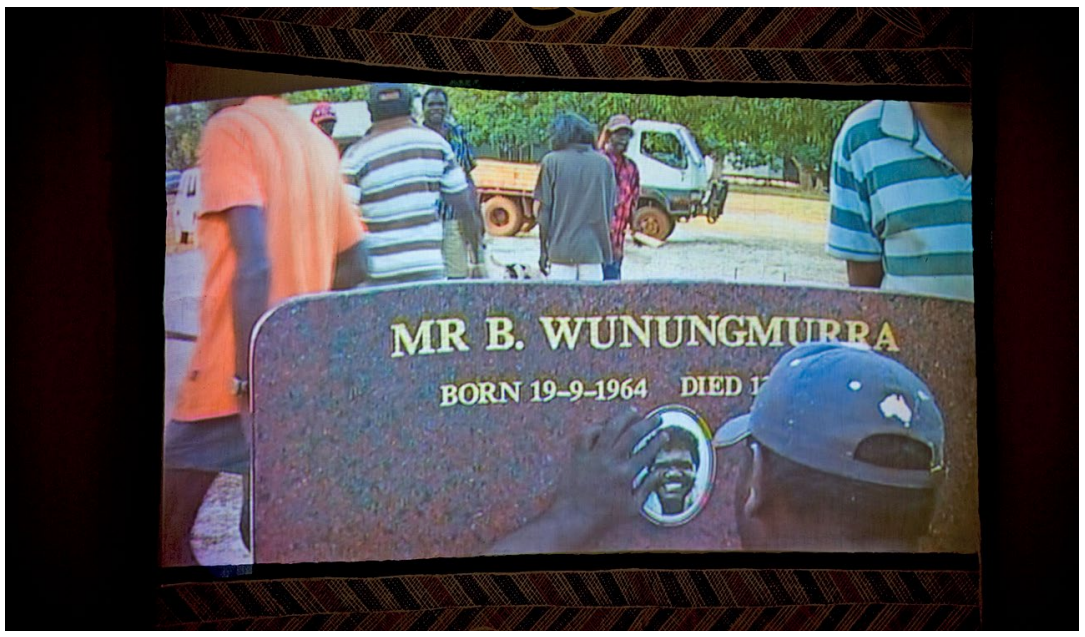

Figure 6.4: Djalkiri \#1 (detail).

Source: Courtesy of the artists.

In the final 20 seconds of the video, the headstone ceremony reaches its conclusion as a photograph of a smiling man is carefully glued into position. From the dates in gold lettering, we can calculate that he 
died aged 37. But we don't know his name. In keeping with current Yolngu conventions it is withheld, indicated only by the initial B. ${ }^{10}$ For me, this is the crucial moment, the point at which the multiple media coalesce. For although his face is only glimpsed briefly at the end of the video - and then only in a photograph - there is indeed a central human figure around which it is structured and organised, a figure who is animated, called forth and made visible.

Created, at my instigation - with his wife, daughter and nephewto be exhibited in a Sydney art gallery among other artworks by anthropologists whose lives have also become densely interwoven with their research subjects, the work acts as a performative homage to the man who became the central and defining figure in my anthropological research in Arnhem Land; a man who, by adopting me, instructing me and working alongside me as a video-maker, profoundly determined the way that Yolngu continue to see me, as much as the way I see them. ${ }^{11}$

10 I have written elsewhere at some length about the shift in Yolngu relations to images of the dead. See Jennifer Deger, Shimmering screens: Making media in an Aboriginal community, Minneapolis, University of Minnesota Press, 2006; and Jennifer Deger, 'Imprinting on the heart: Photography and contemporary Yolngu mournings, Visual Anthropology, vol. 21, no. 4, pp. 292-309.

11 As I wrote for the catalogue at the time:

interventions explores what might happen when researchers, instead of writing about their subjects, take up visual and other media as a way of relating with others. The exhibition claims the possibility of Aboriginal people working creatively with ethnographers to generate new forms and styles of cultural production. Compelled by the idea that making - and viewing - art is a critical and productive form of social engagement, interventions offers new ways of taking up, and taking seriously, Aboriginal ways of seeing the world.

... this exhibition is not aiming at the fine art market ... There are other kinds of economies, other kinds of exchanges at play here. By breaching conventional separations between art practice and scholarship - not to mention between the Indigenous subject and the non-Indigenous researcher-interventions locates artists and ethnographers in shared fields of experimentation.

Jennifer Deger, 'Making interventions', Interventions: Experiments between art and ethnography, Macquarie University, Sydney, 2009, pp. 1-9. 


\section{VI}

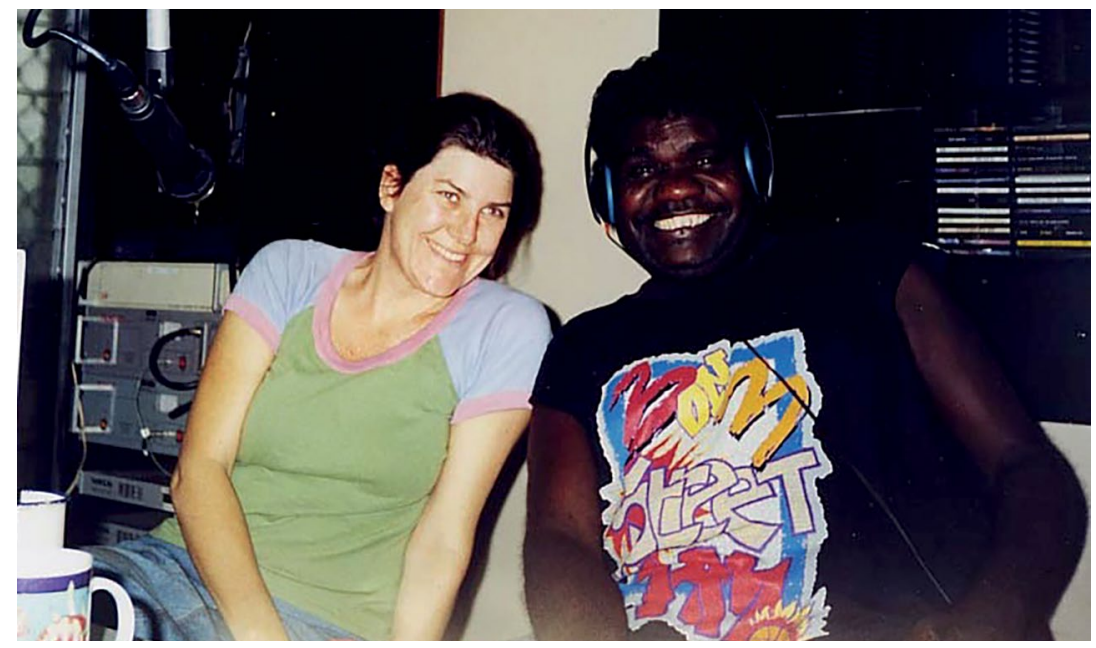

Figure 6.5: Jennifer Deger and Bangana Wununungmurra in the BRACS radio studio, Gapuwiyak 1999.

Source: Jennifer Deger.

I first met Bangana in 1994. He walked into the local community radio station where I was volunteering and announced that he wanted to work there with me. We could, he said, use the technology to strengthen Yolngu culture. Over the next few years, Bangana became my closest Yolngu friend and colleague. He oversaw the insertion of locally recorded manikay (clan songs) and raypirri (instructional messages) into a radio playlist that had previously been filled only with local favourites like ABBA, Smokey, Yothu Yindi, Kenny Rogers and Boney M. We made videos together in SuperVHS, working across northeast Arnhem Land with clan leaders and visiting film crews. He directed. I produced. We translated together. ${ }^{12}$

Looking back over the years since he died, I'm surprised to realise just how many of my films and artworks feature Bangana's image, often incorporating the same photograph. There are many reasons for this: his image summons up his family's identity, our relationships, and by extension my relationship with his family and community;

12 This essay forms a couplet with another piece about the making of this work. See Jennifer Deger, 'Constellations of us: Backstories to a bark TV', Journal of Australian Studies, vol. 35, no. 2, 2011, pp. 219-34. 
it allows us to harness his authority and creative force as a powerful Dhalwangu man; it gestures to an enduring sense of shared loss, a specific set of stories and feelings that have become associated with him over the years. It also locates him as somehow seminal to the unfolding potentialities brought by new generations of digital media; and, of course, as foundational to the self that I have become.

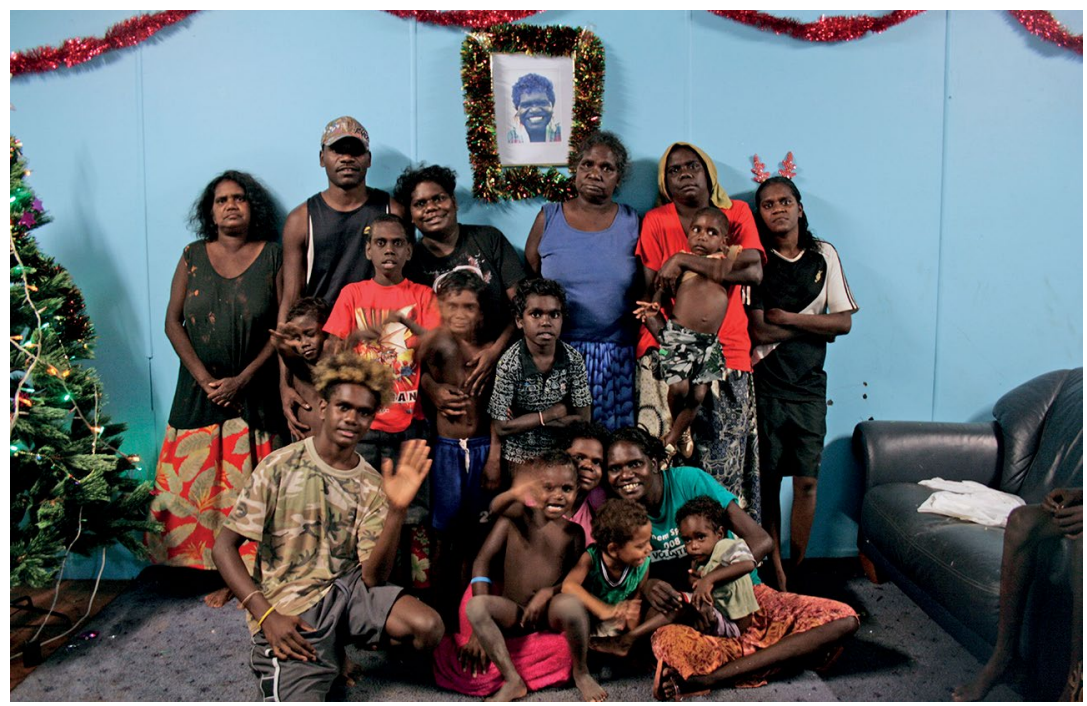

Figure 6.6: Family portrait \#3, Christmas Birrimbirr (Christmas spirit), installation, Miyarrka Media, 2011.

Source: Courtesy of Miyarrka Media.

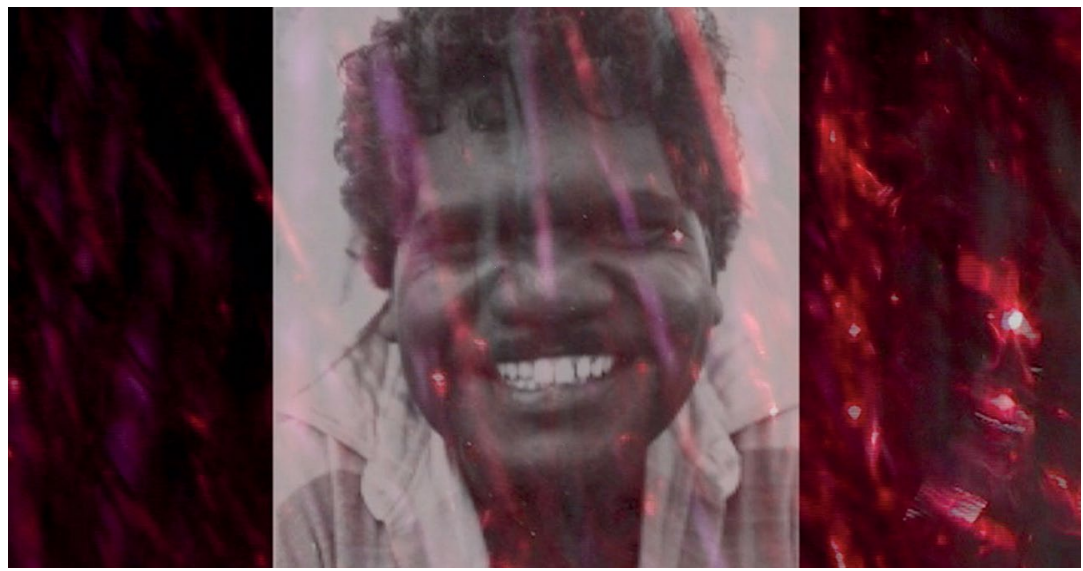

Figure 6.7: Christmas with Wawa (still), Jennifer Deger with Susan Marrawakamirr Marrawungu, 2007.

Source: Jennifer Deger. 


\section{VII}

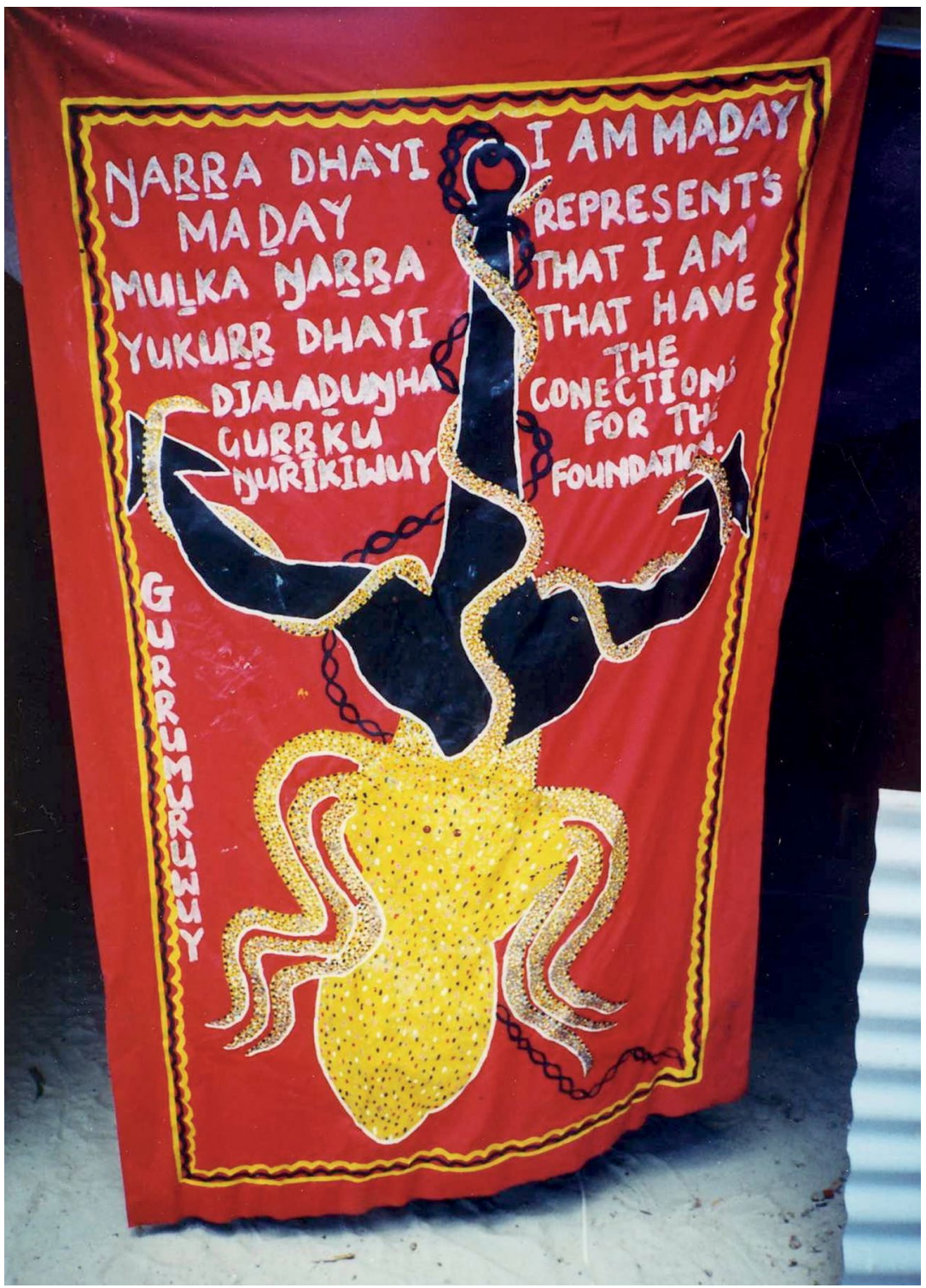

Figure 6.8: The entrance to Bangana Wunungmurra's funeral shade, 2001.

A painted cloth hung at the entrance to the shelter where we held Bangana for two weeks of ritual in the area known as Djalkiri. Amid the field of multicoloured dots on the body of the octopus are two slightly larger ones. These are the eyes.

Source: Jennifer Deger. 
In the months and years after Bangana's death we would sometimes get spooked when we heard an unexpected clank of steel or saw shadows in the trees that looked like wriggling octopus tentacles. In hushed voices, people would tell me how at night the octopus changes colour, depending on its mood.

\section{VIII}

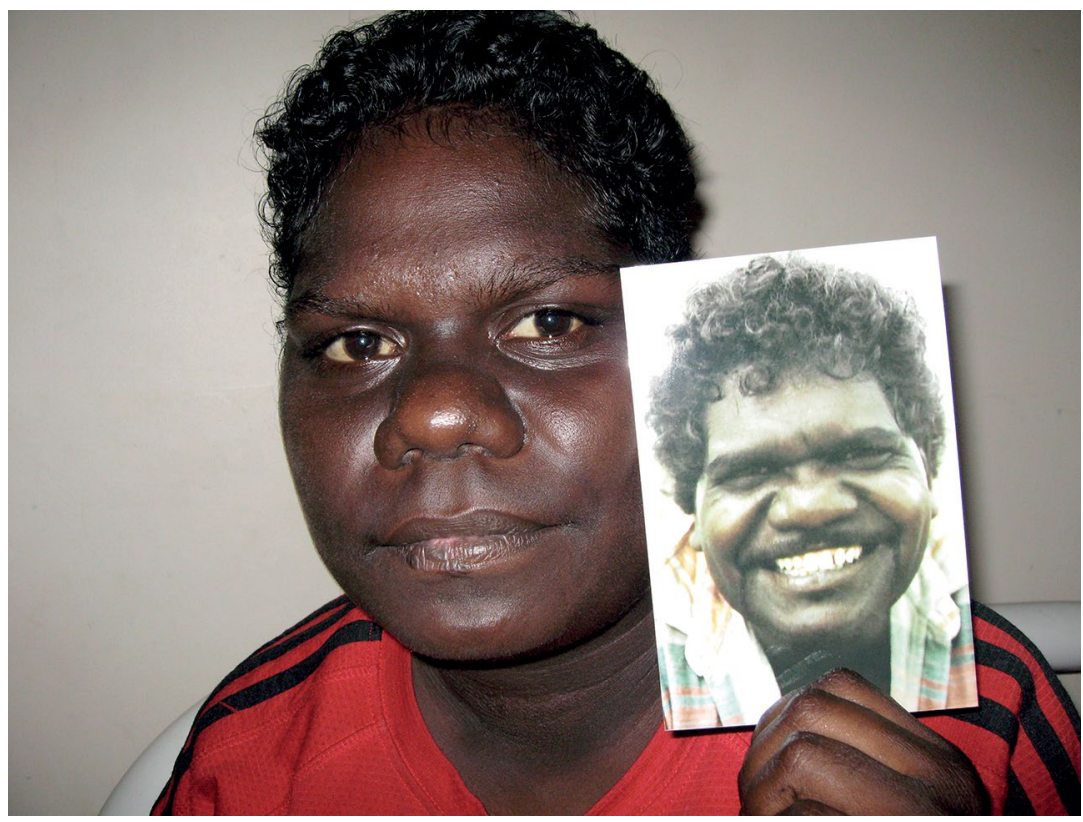

Figure 6.9: Portrait of father and daughter, 2005.

During the months after his death, Bangana's youngest daughter, Lay'pu, made a series of photographs with me, using my digital camera, showing her holding her father's image. We kept going until we got it right. She wanted to capture the likeness, to show their unmistakable connection. I've lost the one where she smiles, the one we both loved, the one shuddering with uncanny likeness.

Source: Jennifer Deger.

\section{IX}

Djalkiri is a Yolngu word for foot or footstep, but in a deeper sense it is used to refer to the underlying foundations of Yolngu life. It is the name given to the house where Bangana Wunungmurra once lived 
and where he is now buried, next to the shady area under the mango tree where his father held ceremonies in the early mission days of the 1970s. For those of us involved in this project, djalkiri means home and belonging, family and foundation, a shared history and a particular point of attachment.

Susan Marrawakamirr Marrawungu, widow of Bangana, her nephew David Bukulatjpi, and I called our work Djalkiri \#1 for all these reasons.

\section{$X$}

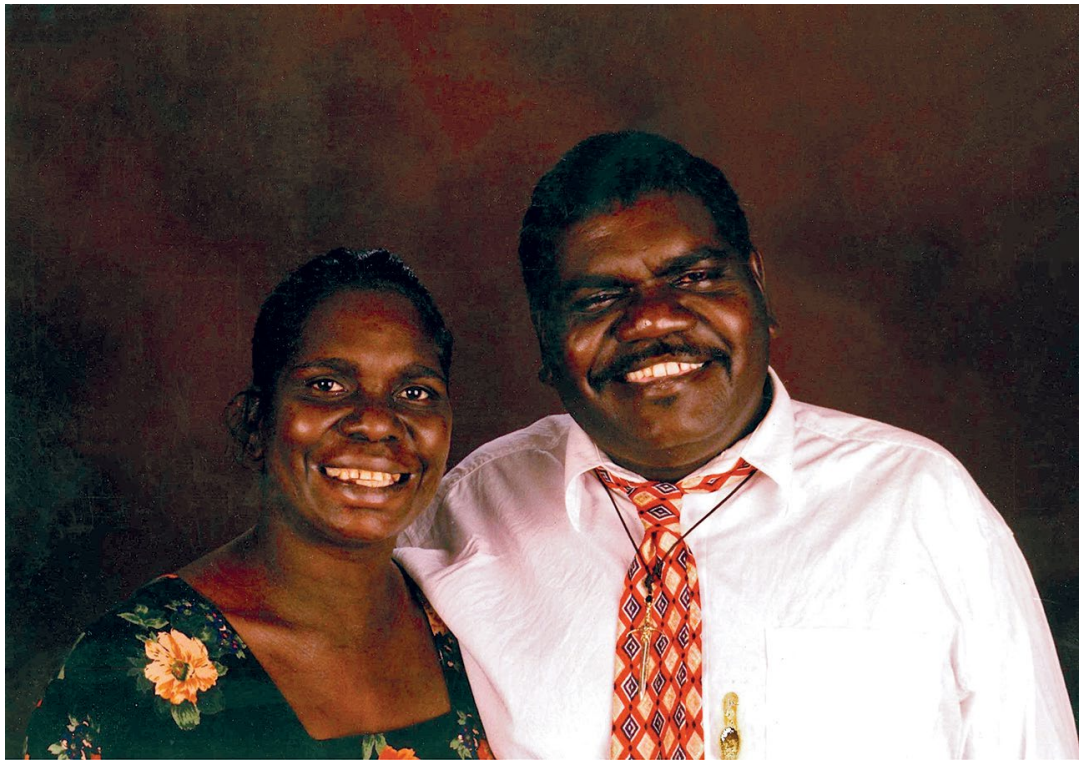

Figure 6.10: Studio portrait of Susan Marrawakamirr Marrawungu and Bangana Wunungmurra, 1997.

Bangana has arranged himself for the camera as loving family man and successful intercultural figure (complete with accidental coffee stain). He's just spoken at his first international conference, a symposium on Indigenous people in an interconnected world.

Source: Jennifer Deger.

In the above image, against the elongated diamonds and colours of his tie hangs a miniature sword, its placement foregrounding not only a Dhalwangu identity but a foundational source of power, force and ferocity. At the Dhalwangu homeland of Gurrumurru, the ancestral 
swordsman called Birrinydji stands with his knives crossed. Bangana's father was named after that knife. As Yolngu say, his name is on that knife - Lawarrwarkk; it also means stingray.

There's a special ritual sound for that knife. In Djalkiri \#l we hear it when the ritual leader hits his steel tools above his head (it doesn't matter what steel is actually used). Men sing that sound too: Ngarrk yarrk. Ngarrk yarrk. In the gallery it rings out: voices, clap sticks, hands and steel in unison.

As Bangana's brother-in-law explained, an imagistic poetics not simply of place but also of emplacement unfolds as the video loops across the bark:

The yiki (knife) clears the ground in preparation: the grader, the backhoe any blade can be used... With the yiki they clear the ground to lay the anchor. That's the foundation: the anchor, the footprint. That heavy anchor (the headstone) is going to be stamped in, stamped in forever. They're putting down the anchor, this is where he's going to stop.

\section{$\mathrm{XI}$}

Anthropologists often use the term 'ancestral power' to identify both the source and subject of Yolngu creativity. We describe the ways that individuals identify themselves based on clan affiliations and complex genealogies. The difficulty with these formulations is that they suggest that Yolngu art and ritual depend entirely on the creative actions of those who came before. This obscures the degree to which this is a two-way street - the way that contemporary innovation is necessary to enliven both current generations and the ancestral.

Such work, however, is not without its risks.

When Bangana died unexpectedly from a heart attack in 2002, Marrawakamirr, Bangana's widow, and his children were in no doubt that the cause of his death was malicious sorcery, and that he was killed because he had exhibited a lethal combination of charisma, talent and wilful genius. ${ }^{13}$ The only question was who, exactly, to

13 See Deger, 2006, 2011. 
blame. Over the years versions of the story have continued to shift and change according to how lives have unfolded, drawing in retrospective insights and changing familial alliances. What hasn't altered is the degree to which they claim he was murdered because of who he was: a brilliant and provocative man, capable and knowledgeable in both men's business and whitefella bureaucracies, an innovative and politically nimble intercultural broker, destined, we had all thought, to lead his community through the difficult times ahead.

Designing his headstone, Marrawakamirr dug out a slightly worn and faded photograph - her favourite because of the look and the smile. She instructed me to boost the colours on the computer and then have the photograph framed in gold and mounted on a red stone, the colour of the Dhalwangu flag. This was a radical move; it was the first headstone in Gapuwiyak ever to feature a photograph. Ten years on it remains the only one.

Bangana had died at a moment of dramatic change in how Yolngu treated photographs of the dead. Until that time it had been standard practice to destroy, or at least hide away, photographs of deceased family members. For me, Bangana's funeral marked the beginning of a different attitude, where photographs might be incorporated into funerals and grieving processes, as, for example, in displaying Bangana's photograph with the coffin. But the act of putting his photo on his headstone pushed things further than I had ever seen before. It performatively claimed his role as a man of 'modern technologies', as he used to describe himself.

And so in death, as in life, Bangana assumed the stance of leader and innovator: fearless, singular and Dhalwangu. His grave became a favoured site for family portraits. 


\section{XII}

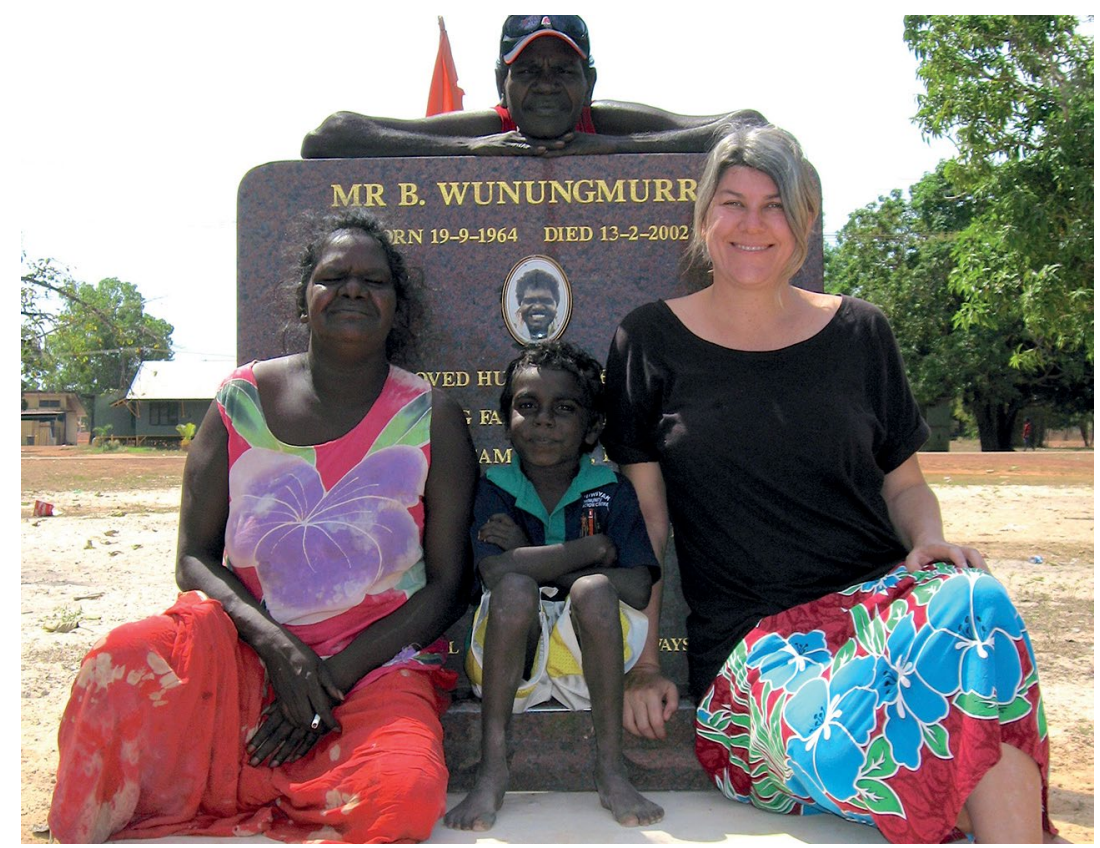

Figure 6.11: Family portrait at grave, 2007.

Source: Jennifer Deger.

I remember trying to deliberately echo Bangana's expression when we took this shot, moved by the relentless good cheer of his image. But on re-encountering my slightly too-bright smile I feel ashamed. What I see here is another moment of an ethnographic clumsiness, a failure to master this subgenre of Yolngu portraiture and self-presentation. I cannot see past my anxiety in the face of the camera. Am I imagining it, or do the others' expressions come from somewhere deeper within? 


\section{XIII}

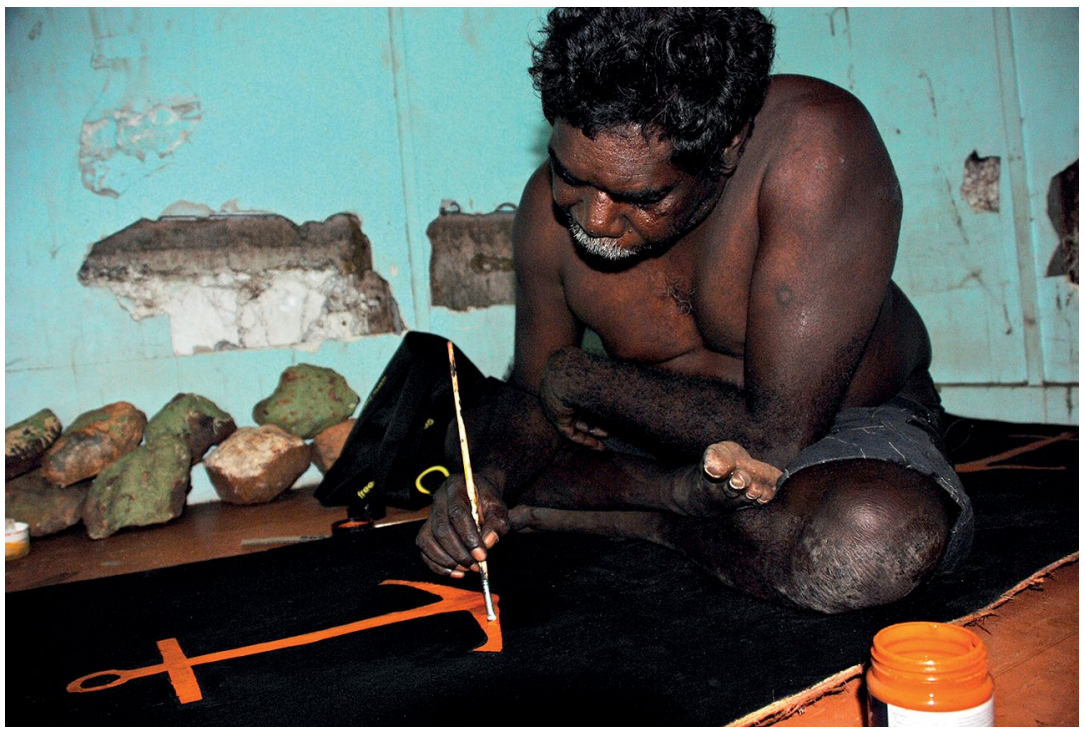

Figure 6.12: David Bukulatjpi painting Djalkiri \#1, 2009.

As a Warramirri man he shares rights and responsibilities for the stories and images associated with Birrinydji. As Susan's sister's son, he was a close and trusted collaborator. This was the first bark he ever painted.

Source: Jennifer Deger.

The photograph above is exactly the kind of photograph that Yolngu never take. In every photo I have ever made with Yolngu, people have chosen to address themselves to the camera. In fact, often they look past the camera, past the particular moment and out to the future reciprocated gaze of family. Increasingly, I think, they look down the lens in anticipation of their death and its aftermath, a time when their relationships will live on through photographs.

When we source archival images from museums, family are often very disappointed when their ancestor does not look at the camera. This is interpreted as an expression of disapproval, not only of the anthropologist pointing the camera, but of the subsequent generations looking at them-looking for a connection with them-all these years later. 


\section{XIV}

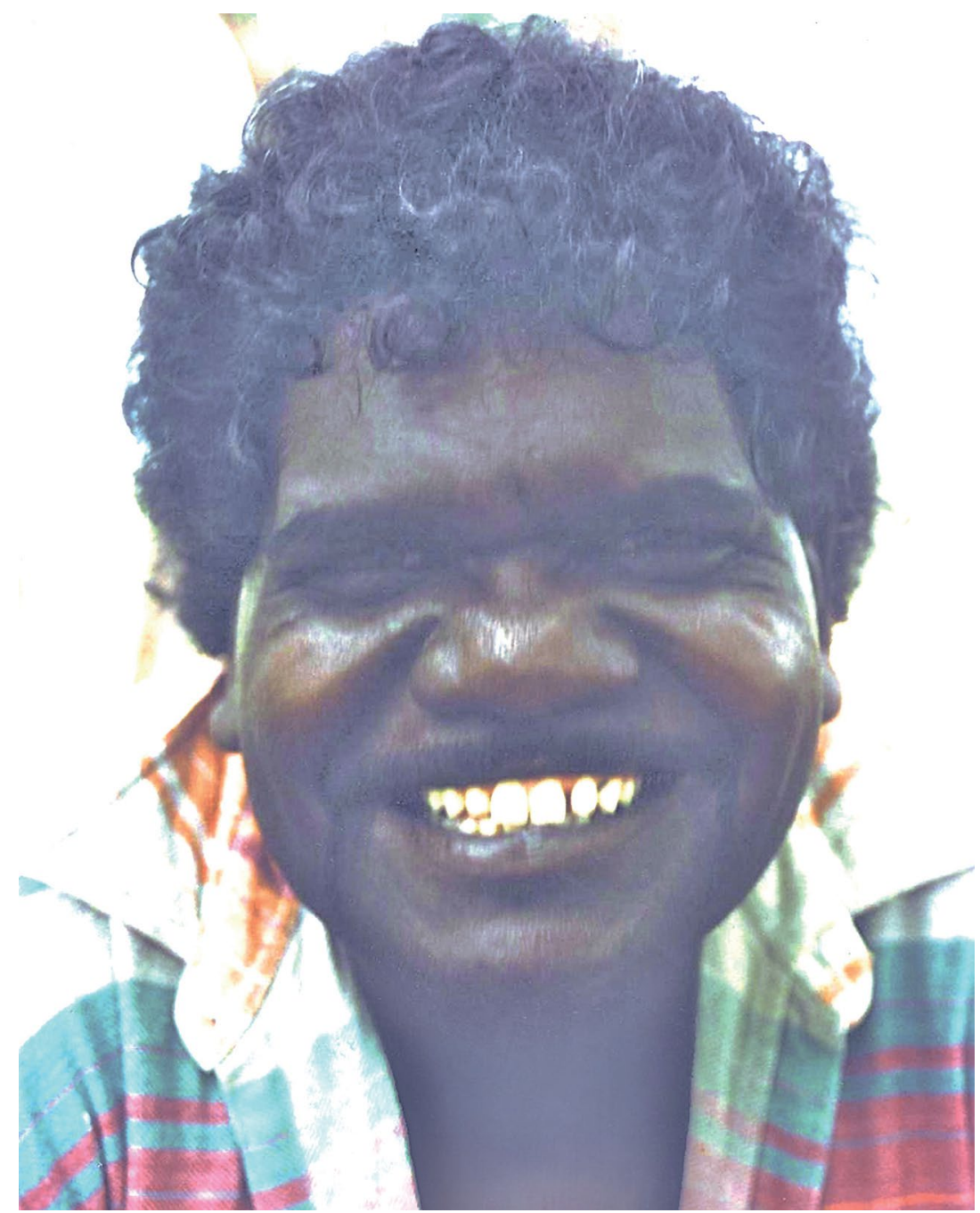

Figure 6.13: Portrait of Bangana Wunungmurra, date unknown.

Source: Jennifer Deger.

Of course not every family photo is a portrait. The image of Bangana repeating throughout was once simply a snapshot. It became a portrait when mobilised in some of the ways I have described: put into relationship with other images and figures so as to bring out and amplify qualities of character in ways that insistently illustrate and affirm the degree to which a Yolngu self is always constituted in and through relationships. 
It occurs to me now that the image above became a portrait even before such projects of loving, insistent remediation. For surely this photo, along with every other image of Bangana where he is captured face on, looking outward to a future not yet imagined, became a portrait exactly in the moment he died: in the moment when the image became an uncanny facsimile of a figure no longer inhabiting fleshly human form. Herein lies a different yet equally wrenching encounter of self with self. One that must be recognised by those left behind.

\section{XV}

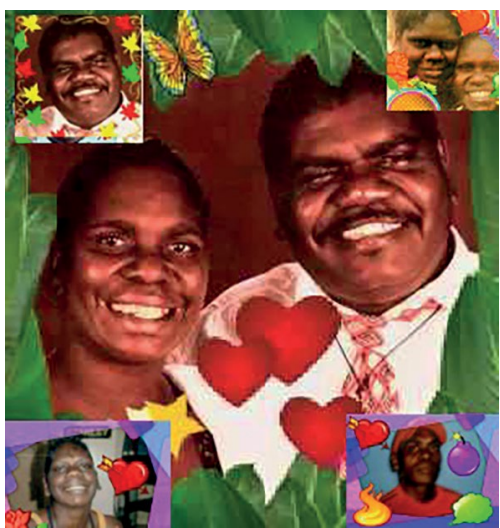

Figure 6.14: ONLY.FAMILY, Rowena Lay'pu Wunungmurra, 2010, phone-made jpeg.

Source: Courtesy of Miyarrka Media.

I am not the only one returning again and again to his face, his eyes and his image. Nor am I the only one mixing media in new ways. Lay'pu assembled this family collage on a mobile phone in 2011, the very making of the photo performing her missing him still, this affective labour shown by the multiple, overlapping hearts, a sentimentality tempered by the losses kept near to the surface. Other elements add to the layered meanings. The wreath of coloured leaves around Bangana's face in the top corner show him to be a reggae lover and serious smoker of marijuana. The leaves also stand in for an element of Dhalwangu identity featured in clan songs. Manjarr, a clan-specific song about a mangrove leaf, simultaneously gestures to images of mangrove leaves 
floating along in saltwater tides, and Bangana's fondness for smoking marijuana (something that Lay'pu also greatly enjoys, and in so doing, sees herself following in her father's footsteps).

These days, many young Yolngu assemble family portraits like these, often including photographs of the dead. They identify them as gamanungu, the same word they use for the designs painted on bark. Often they will add a soundtrack to such images, usually with specially selected manikay (clan songs).

\section{$\mathrm{XVI}$}

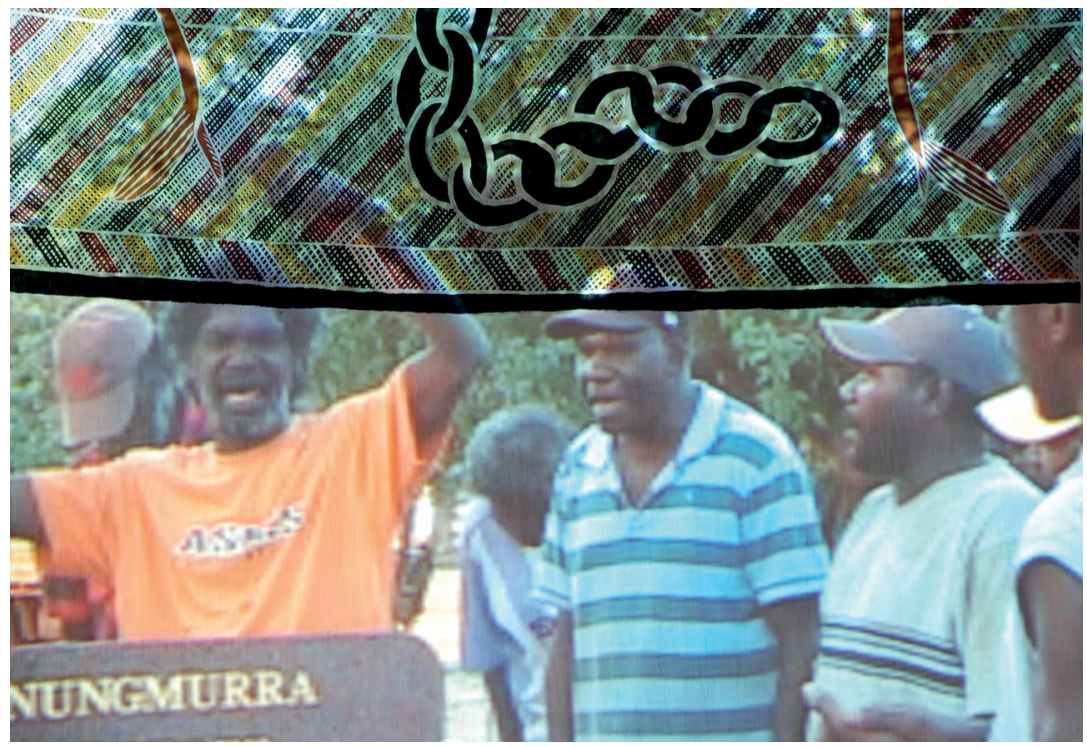

Figure 6.15: Djalkiri \#1 (close-up), during test projections, 2009.

Source: Jennifer Deger.

I like Djalkiri \#1 best when the video bleeds over the lines between the sections, though my Yolngu collaborators prefer the video to sit neatly in its frame, as originally intended. Dhunupa is the word they use to expresses an aesthetic concern with the work of making things straight. The pleasure and sense of correctness that comes from this is not driven by a strict and unbending desire for precision, nor by a sense that there is something intrinsically different about this video and 
its bark painting surrounds, but rather by a concern with attentively ordering things. Straightening something up is a performance of attention and due care, a way of putting things right.

\section{XVII}

The dynamics of encounter run deep in Djalkiri \#1. In both form and content our work claims the transformative potential of intercultural incorporation. As digital sound and movement unsettle the usual sober rectitude of bark painting, our work confidently refuses simplistic categorical separations between 'old' and 'new' technologies or indeed 'them' and 'us'. Like the ritual projected on the bark, the work itself materialises foundational vectors of connection, incorporating the use of 'new' or 'foreign' technologies through a performative poetics of emplacement. While probably no one reading this will ever know the deep stories that lie under the crossed knives and longchained anchors, what comes through strongly - to even the most casual visitor, I hope - is the confident audacity of the work. Perhaps this is what the digital most particularly adds in this context: a multisensorial energy palpably bringing new life to old forms.

When we installed our work in Sydney, we all agreed Bangana would have been pleased. Hanging prominently in a Balanda institution, this artwork is one for posterity: one that puffs its chest just a little, assuming its place on the wall, eyes to the future, uniquely distinctive and Yolngu in equal measure.

Certainly this is not portraiture as it matters to Nancy. The inner psychic disunities that compel his analysis do not interest Yolngu in the same ways. Instead, the gesture - whether in ritual, painting or photography - is towards an expanded and outward-orientated sense of becoming-in-relationship. This brings with it a very different sense of the self-to-self dynamics that make us who we are, and consequently a very different sense of the fault lines of fragility and hubris that, if exposed, might allow others to see the stuff from which we are really made.

If portraits compel us because of the ways they attend to the delicate and all-too-human relationships of selves encountering other selves, then this work both conforms to the definition and extends it. 
By 'framing' contemporary life in relation to ancestral figures and actions, Djalkiri \#1 asserts - like all Yolngu art - that Yolngu selves extend far beyond individuated human form. Here the symbols of knives and anchors assert Bangana's identity and, by extension, his knowledge and power, as decisively as the books in Bronzino's Portrait of Ugolino Martelli do the same for that subject. Yet what makes this work unlike a 'traditional' bark painting - and thus arguably more like a portrait - is the way the pathos of the smiling human figure on the headstone undercuts the heroic postures painted directly on the bark. For those of us who live with the enduring fear, suspicion and blame that settled around the Djalkiri family in the wake of Bangana's death, this sense of human vulnerability as an integral aspect of claiming and wielding 'ancestral power' is a palpable dimension of the work. In a minor and manageable way, the work triggered these anxieties anew. Prior to commencing there were long discussions between us, as well as permissions sought from others, in order to ensure we were not committing any transgression in the use of the painted figures. The last thing any of us wanted was to stir things up again. And yet in a way it felt inevitable. And strangely proper. Bangana had always made it clear to me that in order to do such work - to publicly show who he was through the ways he used new media-would always be risking criticism and jealousy from others. The challenge, as he explained it to me, was to be as circumspect as possible in regard to the revelation of ancestral knowledge, while finding new forms and forums for it. In this way, he managed what I have called elsewhere a politics of presencing. ${ }^{14}$

Yet I too occupy a place within the bark, a fact often acknowledged by my collaborators, who, despite their interest and critical help in making sure the work satisfied all Yolngu social and aesthetic criteria, saw this artwork ultimately as my project. (Like the photograph on the gravestone, the BarkTV remains a one-off. There has been no interest in pushing this mixed-media further, although we have experimented with other forms of bark projection.) Assuming my place as filmmaker-anthropologist-adopted clan member-often when I film I am encouraged to come closer than the other women, for the sake of the recording - my point of view frames and fills the middle panel.

14 See Deger, 2006. 
In doing so it invokes a shared history of media-making, locating this work within a trajectory of innovation and experiment begun when we were all young together.

And so Djalkiri \#1 materialises the verve and genius located not in individuals, nor even necessarily cultures, but in the foundational relationships that make us who we are - and who we might become. Although lacking the kind of recognisable immediacy generally expected from a portrait, this ethnographic experiment offers an encounter with an expanded sense of what it means to be human: an encounter less concerned with the fleshiness of figures or the fragile markings of individual character than with the pulsing substrates that extend beyond and beneath the span of a single life.

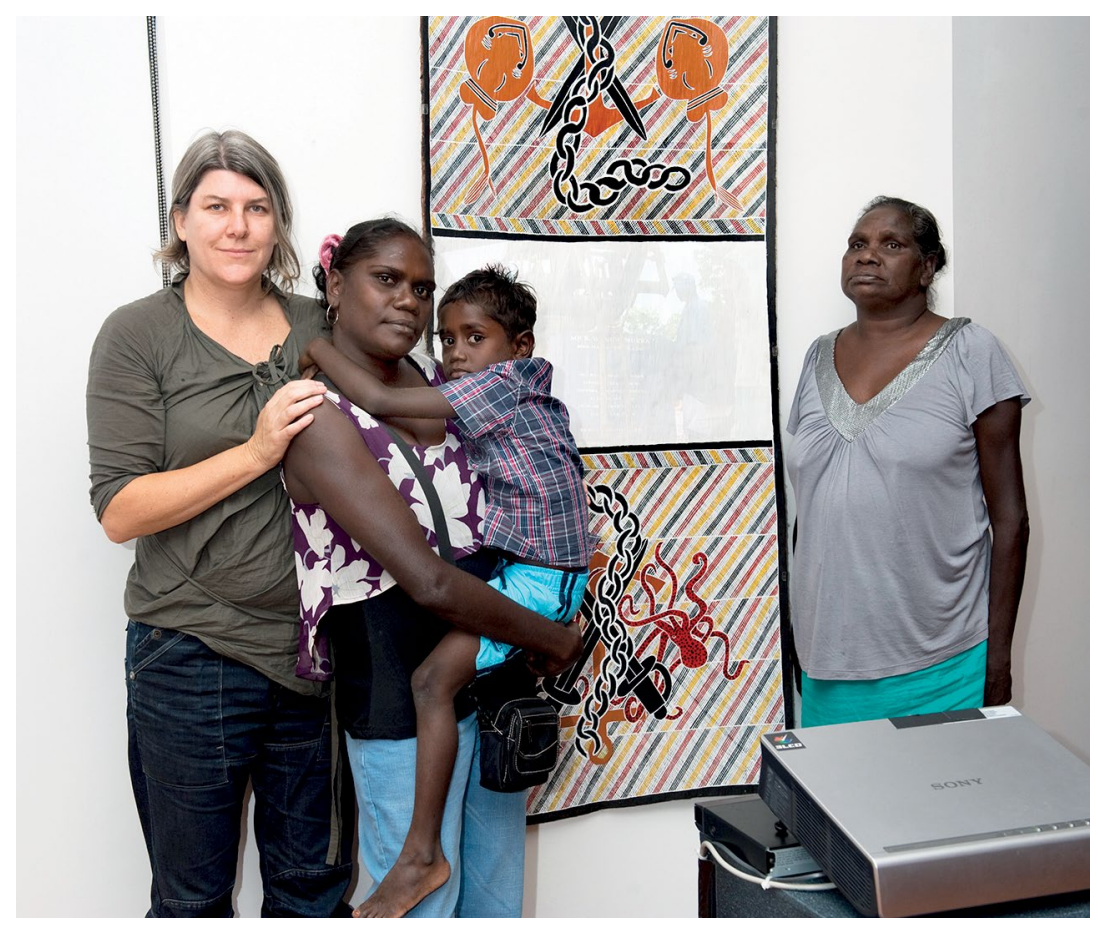

Figure 6.16: Jennifer Deger, Samantha Yawulwuy Wunungmurra, Antonnio Gurrururu Wanambi, Susan Marrawakamirr Marrawungu, Macquarie University Art Gallery 2009.

Source: Courtesy of Macquarie University Art Gallery. 


\section{Acknowledgements}

Many thanks especially to Marrawakamirr Marrawungu, Yawulwuy Wunungmurra, David Bukulatjpi, Wapit Munungurr and Yangipuy Wanambi for all their input into the exhibition and my understandings of it. The Djalkiri family have generously given permission for the use of the photographs and images that appear in this chapter. Much gratitude also to Jane Sloan, Melinda Hinkson and Alison Leitch for reading unwieldy early drafts; and again to Melinda Hinkson for her invitation to think about our work in these ways. I am grateful especially to Greg Downey and Rhonda Davis at Macquarie University for their energetic support of the interventions exhibition. An Australian Research Council Postdoctoral Fellowship and a Future Fellowship supported the research that eventually resulted in this essay. Finally, I am grateful for the support of the Cairns Institute at James Cook University. 
This text is taken from Imaging Identity: Media, memory and portraiture in the digital age, edited by Melinda Hinkson, published 2016 by ANU Press, The Australian National University, Canberra, Australia. 